\title{
Neumonía eosinofílica crónica
}

\section{Chronic eosinophilic pneumonia}

\author{
Leidy Samara PInILla Quintero, MD.(1); JaVIer EnRIQUe Fajardo Rivero, MD. ${ }^{(2)}$
}

\section{Resumen}

La neumonía eosinofílica crónica es una entidad poco frecuente y estudiada en nuestro medio, cuyo diagnóstico se basa inicialmente en la sospecha clínica y los antecedentes comunmente asociados como atopia o asma; sin embargo, no todos los casos se presentan como lo describe la literatura científica.

Se expone el caso de un paciente previamente sano, con un cuadro crónico de tres meses de tos y síntomas constitucionales que no mejoraron a pesar de múltiples esquemas antibióticos de forma empírica y con persistencia de múltiples opacidades de compromiso alveolar con broncograma aéreo y áreas de consolidación de predominio basal bilateral. Se realizó fibrobroncoscopia y lavado broncoalveolar con evidencia de eosinofilia pulmonar, hallazgo que determinó el diagnóstico de neumonía eosinofílica crónica, sin realización de biopsia. Una de las pruebas para confirmar el diagnóstico es la respuesta a la terapia esteroidea, dejando como última opción las medidas invasivas.

Un alto índice de sospecha clínica, la documentación de eosinofilia periférica y/o pulmonar y la respuesta al tratamiento con corticoides deberían ser suficientes para el diagnóstico definitivo de neumonía eosinofílica crónica, en los casos en los que no es posible realizar biopsia pulmonar.

Palabras clave: eosinofilia, eosinofilia pulmonar, neumonía eosinofílica crónica, neumonía eosinofílica, enfermedad de Carrington.

\begin{abstract}
Chronic eosinophilic pneumonia is, in our milieu, an uncommon and little-known condition. Its diagnosis is initially based on clinical suspicion and commonly associated conditions, such as atopia or asthma; however, not all cases appear as described in the scientific literature.

We present the case of a previously healthy patient, with a 3-month history of cough and constitutional symptoms that did not improve despite multiple empirical antibiotic schemes. Chest radiographs showed persistent alveolar opacities, with air bronchogram and predominantly basal, bilateral areas of consolidation. Fibrobronchoscopy and bronchoalveolar lavage were performed; pulmonary eosinophilia was evidenced. This finding determined the diagnosis of chronic eosinophilic pneumonia, without biopsy being performed. One of the tests that confirms this diagnosis is response to steroid therapy; invasive measures should be left as a last option.
\end{abstract}

A high index of clinical suspicion, documentation of peripheral and/or pulmonary eosinophilia, and response to corticoid therapy should be enough to reach a final diagnosis of chronic eosinophilic pneumonia, in cases where lung biopsy is not possible.

Keywords: eosinophilia, pulmonary eosinophilia, chronic eosinophilic pneumonia, eosinophilic pneumonia, Carrington's disease

\section{Caso}

Paciente de género masculino, de 51 años de edad, quien consultó por cuadro clínico de tres meses de evolución que inició con congestión nasal, rinorrea hialina, astenia y adinamia, con posterior aparición de tos seca y fiebre no cuantificada recibiendo tratamiento por siete días con amoxicilina
${ }^{(1)}$ Residente de primer año de Medicina Interna, Universidad Autónoma de Bucaramanga. Bucaramanga, Colombia.

${ }^{(2)}$ Especialidad: Medicina Interna-Fellow Neumología, Universidad de la Sabana. Bogotá, Colombia

Correspondencia: Leidy Samara Pinilla Quintero, correo electrónico: samara_pinilla (a)yahoo.es

Recibido: 15/05/15. Aceptado: 25/05/15. 
-clavulanato, luego ampicilina-sulbactam por siete días, y ceftriaxona por 12 días de forma domiciliaria, con lo que se observó mejoría parcial de la sintomatología. Sin embargo, consultó nuevamente por urgencias debido a reagudización de tos seca, pérdida de peso no intecionada de $8 \mathrm{~kg}$ durante el período de su enfermedad asociado a sudoración nocturna.

Dentro de sus antecedentes patológicos se destaca fístula arteriovenosa cerebral con embolización a los 44 años de edad y sinusitis crónica, sin historia de atopia ni enfermedades respiratorias del tracto respiratorio inferior previas, exposición a humo de tabaco durante 30 meses, 5 cigarrillos día, sin otras exposiciones establecidas como medicamentos diferentes a acetaminofén; antecedente familiar en primer grado de consaguinidad con Linfoma Hodgkin.

Al ingreso al servicio de urgencias se identificó FC: 100 min, FR: 17 min, Saturación: 98\% PA: 137/ $83 \mathrm{~mm} \mathrm{Hg}$. Cuello sin adenopatías, no ingurgitación yugular, expansión torácica adecuada, auscultación de ruidos cardiacos rítmicos, no evidencia de soplos, pulmones con ruidos respiratorios disminuidos de predominio basal derecho con estertores finos en base izquierda, frémito táctil y vocal conservado, sin tirajes. Abdomen depresible sin organomegalias ni signos de irritación peritoneal. Extremidades sin edemas, acropaquia o cianosis. Estable desde el punto de vista neurológico, sin alteración al examen clínico, alerta y sin focalización.

El resultado de hemograma no mostró alteración, Hb: 13,9, Hto:43,1, Leucocitos:10.550, N: 77,9\%, L: $12,7 \%$, eosinófilos $1,3 \%$, plaquetas: 316.000 con aumento de reactantes de fase aguda PCR 56,4 mg/l y procalcitonina menor a $0,2 \mathrm{ng} /$, sin otra alteración en los exámenes bioquímicos.

En el perfil de inmunidad se encontró elevación de los anticuerpos anti Ro: 96,4 (valor de referencia menor a $25 \mathrm{U}$ ).

Se tomó Radiografía de tórax que mostró opacidades alveolares confluentes en el lóbulo inferior derecho, sin alteración de los hilios pulmonares ni en la vascularización pulmonar (figura 1), así como tomografía de alta resolución de tórax que evidenció múltiples opacidades de compromiso alveolar con broncograma aéreo y áreas de consolidación que comprometían los lóbulos inferiores izquierdo y derecho, y bandas de atelectasia plana en regiones posteriores y basales. También se observaron bandas de atelectasia plana en el lóbulo superior derecho sin lesiones pleuropulmonares de tipo evolutivo (figura 2).

Estudios adicionales incluyeron perfil de autoinmunidad, IgE sérica, pruebas de función renal y hepática normales, estudios de esputo como baciloscopia seriada, cultivos para gérmenes comunes, hongos, micobacterias y demás coloraciones negativas, con evidencia de eosinofilia pulmonar dada por conteo en el LBA del 30\% (tabla 1, figura 3).

\section{Discusión}

La neumonía eosinófila crónica (NEC) hace parte de un grupo heterogéneo de trastornos que se caracterizan por eosinofilia periférica y/o pulmonar.

La prevalencia de dicha entidad no ha sido estimada en Colombia; existen datos reportados en Europa que muestran un porcentaje entre $0-2,5 \%$ (1), lo que hace que esta sea poco frecuente y se desconozca su comportamiento real en nuestro medio.

Las manifestaciones clínicas son inespecíficas y se necesitan datos que ayuden a sospechar el diagnóstico, como la persistencia de síntomas que varían desde tos, disnea, pérdida de peso, sudoración nocturna, con un tiempo promedio de presentación de síntomas antes del diagnóstico entre 4 a 5 meses (2).

Esta entidad es más frecuente en mujeres con una relación 2 a 1 y cerca de un tercio de los pacientes tienen antecedente de asma o historia de atopia asociada a eosinofilia periférica y/o pulmonar.

El caso expuesto, hombre, previamente sano, sin antecedentes patológicos relevantes, quien recibió tres esquemas de antibiótico en el transcurso de tres meses, sin eosinofilia periférica describe el comportamiento subagudo o crónico e inespecífico de esta entidad, cuyo diagnóstico genera un desafío en la práctica clínica. 


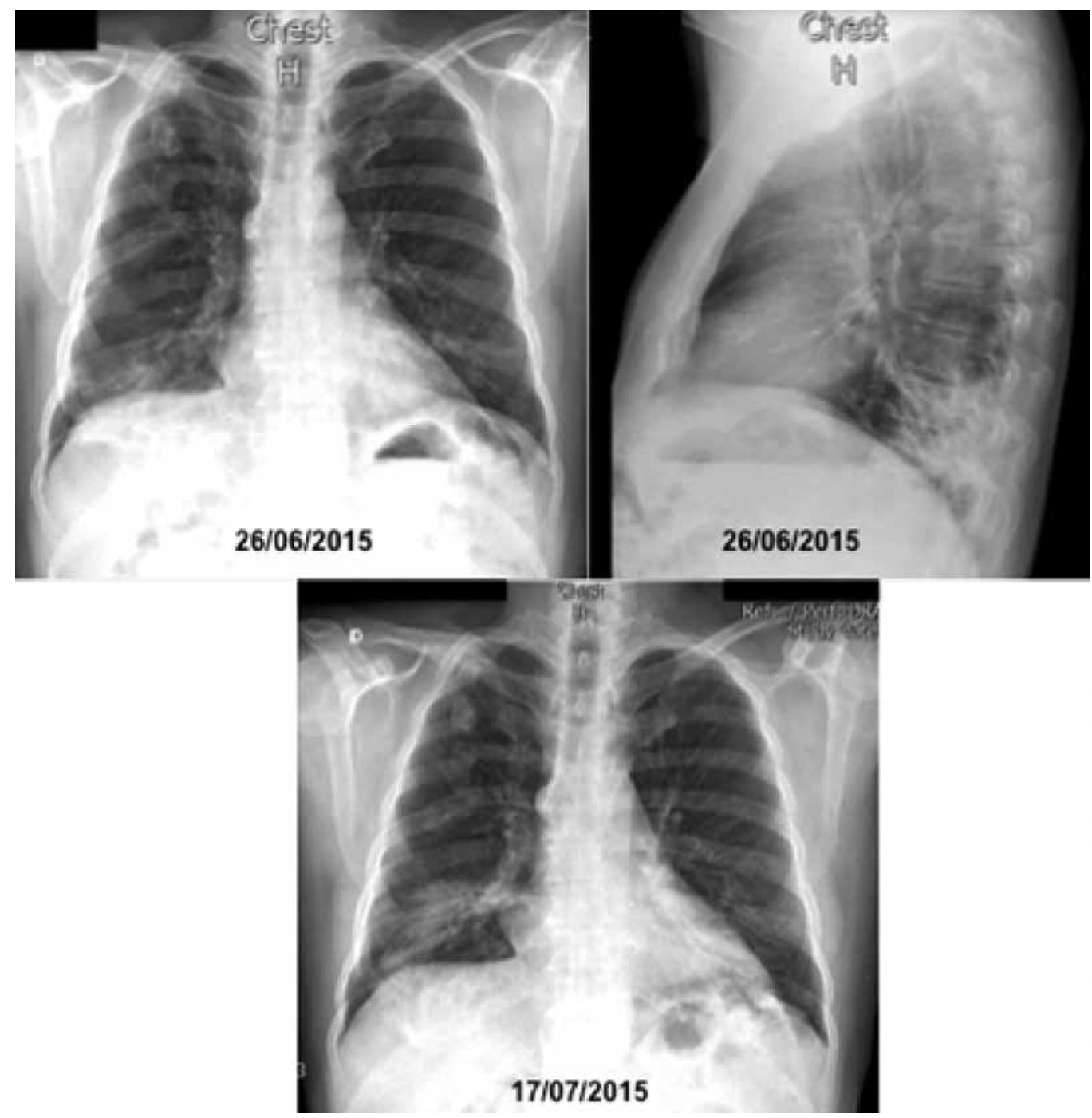

Figura 1. Opacidades alveolares confluentes en el lóbulo inferior derecho.

De otro lado, el lavado broncoalveolar es una gran ayuda diagnóstica en los casos en los que no hay evidencia de eosinofilia periférica y en los que se requiere descartar infección, ya que no hay un patrón radiológico patognomónico de la enfermedad.

En este caso se descartaron vasculitis, entre ellas enfermedad de Churg-Strauss, en tanto que el perfil de autoinmunidad mostró elevación de los anticuerpos anti-Ro; sin embargo no hubo estigmas clínicos de enfermedad del colágeno u otros anticuerpos en la caracterización de alguna entidad específica ni se encontró elevación de la IgE sérica.
A pesar de que no se tomó coproscópico en búsqueda de enfermedad parasitaria, se administró un esquema de erradicación de corta duración con albendazol por tres días, previo al inicio de terapia con corticoides.

Luego de dos semanas de tratamiento con prednisona $1 \mathrm{mg} / \mathrm{kg} /$ día en las primeras 48 horas, seguidos de $0,5 \mathrm{mg} / \mathrm{kg} /$ día, manifestó mejoría notoria en su sintomatología dada por ausencia de tos, disnea y se reintegró a sus actividades cotidianas.

Posteriormente, se realizó radiografía de tórax (figura 4) que mostró una disminución notable de las 

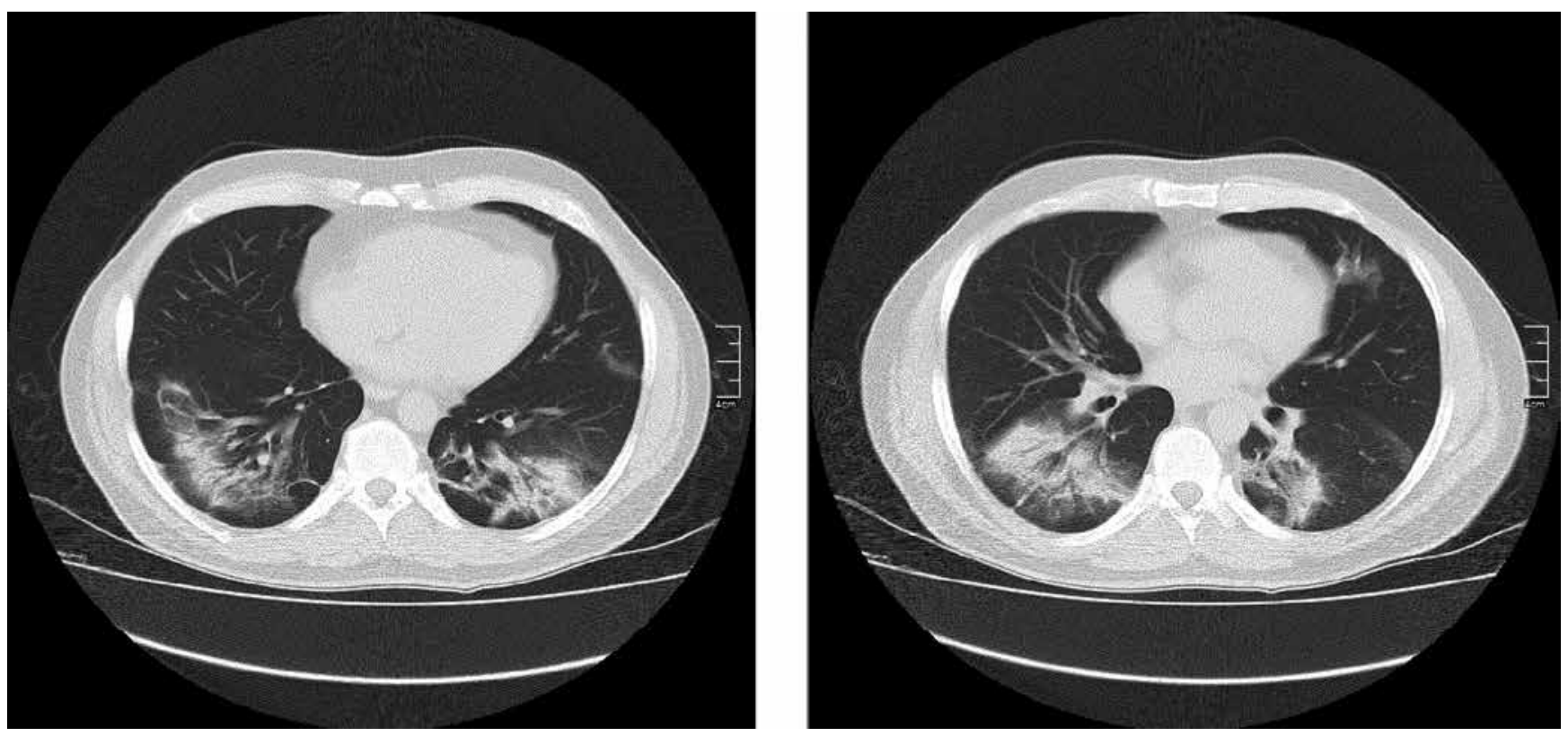

Figura 2. Opacidades de compromiso alveolar con broncograma aéreo y áreas de consolidación en el lóbulo inferior izquierdo y lóbulo inferior derecho.

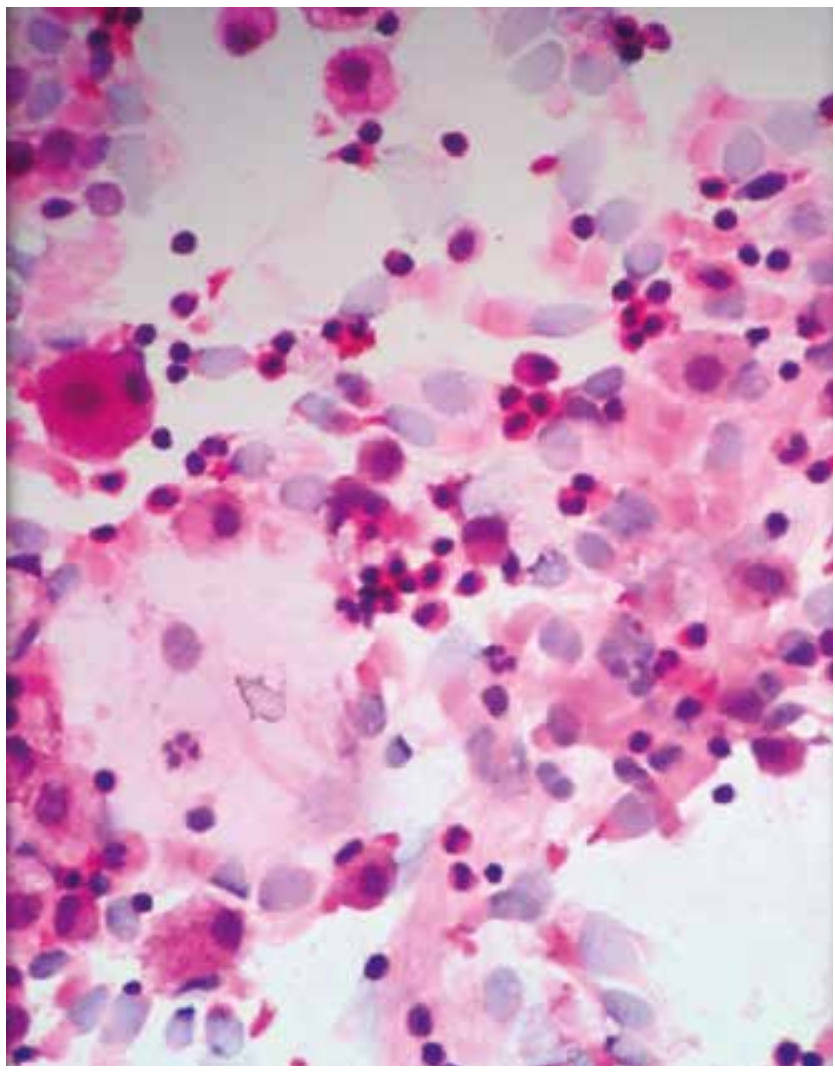

Figura 3. Extendido citológico que evidencia la presencia de abundantes eosinófilos.
Tabla 1. Recuento celular inflamatorio.

Neutrófilos $10 \%$
Histiocitos $50 \%$
Eosinófilos $30 \%$ (forman algunos agregados)
Linfocitos $10 \%$
Otros hallazgos: células inflamatorias descritas en el
recuento, células bronquiales ciliadas y escamosas
benignas.
No se observan células tumorales, ni microorganismos

opacidades alveolares en el lóbulo inferior derecho, observadas específicamente en la proyección frontal.

El hemograma no mostró alteración, ni eosinofilia periférica y la PCR disminuyó de forma significativa. No hay información que sugiera qué estudios deben realizarse para evaluar el seguimiento, así como tampoco hay recomendaciones sobre radiografía o tomografía, o utilidad del LBA como seguimiento; en este caso se optó por el el menos invasivo sumado a la ausencia de sintomatología. 


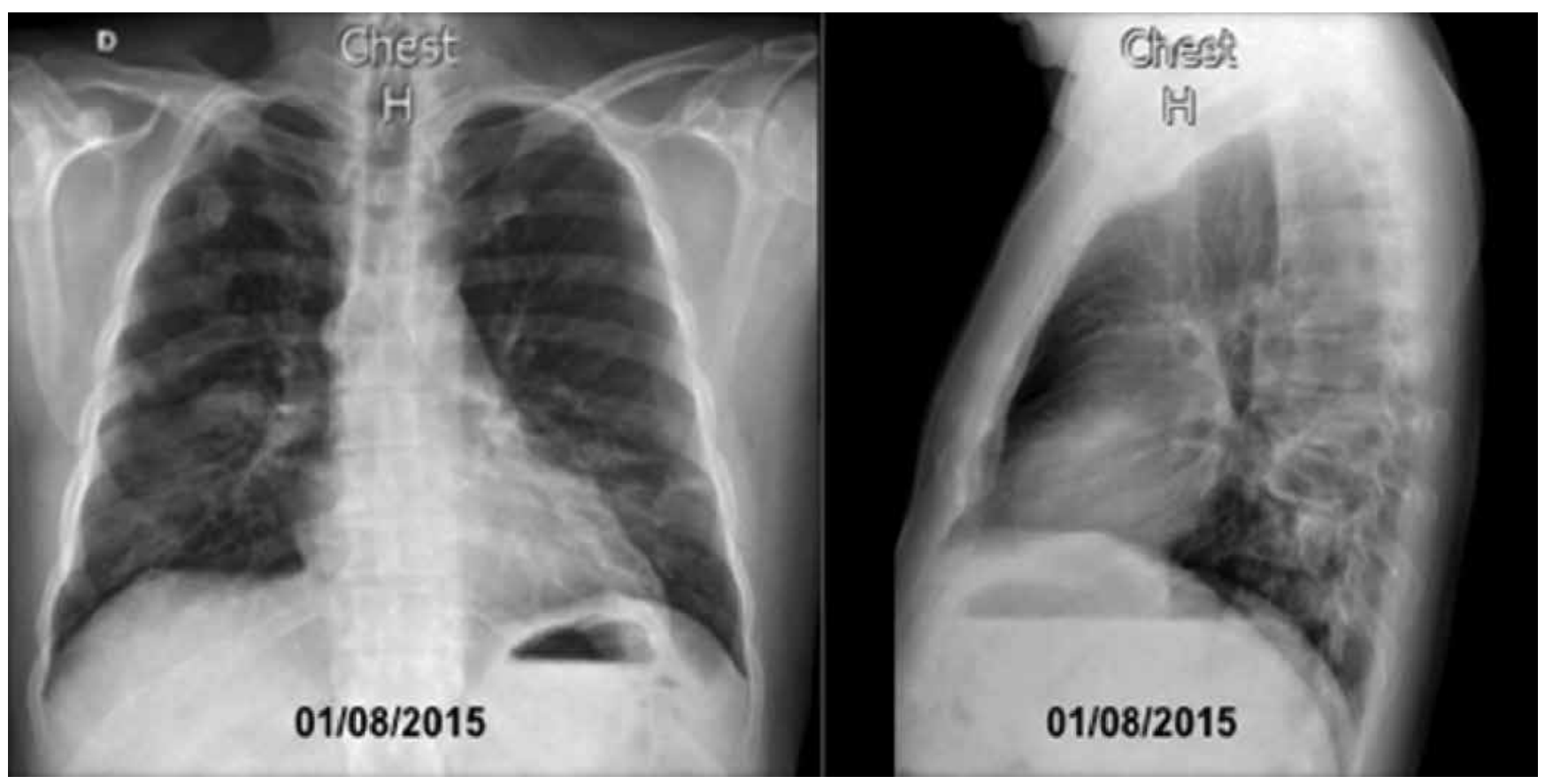

Figura 4. Proyección radiográfica de tórax después de una semana de tratamiento con prednisona.

Por lo anterior, el mejor enfoque diagnóstico está basado en un alto índice de sospecha clínica, el comportamiento subagudo o crónico y la existencia de eosinofilia periférica y/o pulmonar. El lavado broncoalveolar sería la prueba inicial para confirmar el diagnóstico y solo en los casos en los que no hay evidencia de eosinofilia, se consideraría la biopsia pulmonar.

Una vez descartadas otras causas de eosinofilia pulmonar, podría hacerse una prueba terapéutica con corticoides; en este caso la mejoría después de tan solo dos semanas apunta hacia el diagnóstico de neumonía eosinofílica crónica.

No hay estudios que relacionen la positividad de los anticuerpos anti-Ro con neumonía eosinofilica crónica, de ahí que el paciente debe continuar en seguimiento estricto; en este caso se planteó esquema con corticoides por tres meses inicialmente, aunque el tiempo de tratamiento a largo plazo no ha sido establecido, las recomendaciones actuales deben basarse en el seguimiento clínico y el riesgo de recaída.
No es común pensar en neumonía eosinofílica crónica en el abordaje inicial de un paciente que no cumpla con las asociaciones comúnmente descritas, sin embargo es posible concluir que:

1. Esta enfermedad es infrecuente y no se cuenta con datos de prevalencia en nuestro medio.

2. El caso presentado no demuestra rasgos clínicos ni paraclínicos usualmente descritos en la literatura.

3. Los hallazgos del LBA y la respuesta al tratamiento con corticoides apoyan el diagnóstico emitido.

4. Siempre se deben contemplar los diagnósticos alternos de eosinofilia pulmonar antes de iniciar una prueba terapéutica con corticoides (9).

\section{Bibliografía}

1. Ajani S, Kennedy CC. Idiopathic acute eosinophilic pneumonia: A retrospective case series and review of the literature. Respiratory Medicine Case Reports, 2013;10:43-7. doi. org/10.1016/j.rmcr.2013.06.005

2. Cl C. Neumonía eosinofílica crónica. 2010:1133-40. 
3. Lahoz Tornos A, Orcastegui Candial JL. Neumonía eosinófila crónica en la provincia de Soria (1995-2004). Revisión de la bibliografía. Revista Clínica Española. 2009(3):131-135. doi. org/10.1016/S0014-2565(09)70878-1

4. Lee KN, Kim KN, Kim JS, Kwon WJ. Diseases: a clinical, radiologic and patho- logic overview 1 OBJECTIVES. 2007,617-38.

5. Marchand E, Cordier JF. Idiopathic chronic eosinophilic pneumonia. Sem Resp Crit Care Med. 200627(2), 134-141. /doi. org/10.1186/1750-1172-1-11.

6. Montgomery ND, Dunphy CH, Mooberry M, Laramore A, Foster MC, Park SI, et al. Diagnostic complexities of eosi- nophilia. Arch Pathol Lab Med. 2013;137(2), 259-269. doi. org/10.5858/arpa.2011-0597-RA

7. Tzilas V, Bastas A, Koti A, Papandrinopoulou D, Tsoukalas G. A 77 year old male with peripheral eosinophilia, pulmonary infiltrates and a small pleural effusion. Eur Rev Med Pharmacol Sci. 2009;13(3):227-32.

8. Khasawneh KR, Mahmood T, Halloush RA, Khasawneh FA. A neumonia that will not go away. 2014;21(2):80-2.

9. Sano S, Yamagami K, Yoshioka K. Chronic eosinophilic pneumonia: a case report and review of the literature. Cases Journal. 2009;2:7735. doi.org/10.4076/1757-1626-2-7735 